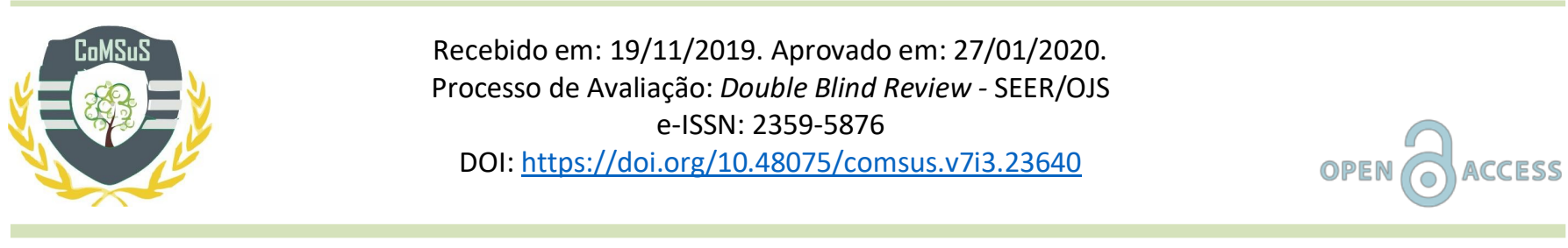

\title{
A Mensuração da competitividade nas exportações agropecuárias: uma análise empírica
}

\author{
Measuring competitiveness in agricultural exports: an empirical analysis
}

Lucas Silva Ramos ${ }^{1}$

\section{Resumo}

A competitividade durante séculos vem sendo cenário de diversas discussões de sua mensuração. $\mathrm{E}$ este é um importante campo a ser estudo, devido a ele ser levado em consideração nas perspectivas cientificas. Assim, se encontra o quão um produto, ou nação é competitiva através dos métodos existentes, como estão sendo aplicados e quais os principais estudiosos sobre o tema. Diante disso, este trabalho buscou identificar as metodologias mais usadas para mensurar a competitividade das exportações no mundo, com destaque para Brasil, utilizando-se de uma revisão bibliométrica como metodologia. Existem muitos métodos disponíveis para essa mensuração, sendo a mais usada com os termos da pesquisa o Índice de Vantagem Comparativa Revelada (IVCR), Constant Market Share (CMS) e Índice de Orientação Regional (IOR) as mais utilizadas no mundo e no Brasil.

Palavras-Chave: Agronegócio; Comércio Internacional; Constant Market Share; Índice de Vantagem Comparativa.

\begin{abstract}
Competitiveness for centuries has been the scene of several discussions of its measurement. And this is an important field to study because it is taken into account in scientific perspectives. Thus, one finds how competitive a product or nation is through existing methods, how they are being applied, and who are the leading scholars on the subject. Given this, this work sought to identify the most used methodologies to measure the competitiveness of exports in the world, especially Brazil, using a bibliometric review as a methodology. There are many methods available for this measurement, the most commonly used with the search terms being the Revealed Comparative Advantage Index (IVCR), Constant Market Share (CMS) and Regional Orientation Index (IOR) the most widely used in the world and in Brazil.
\end{abstract}

Keywords: Agribusiness; International trade; Constant Market Share; Comparative Advantage Index

Cite as: (APA)

Ramos, L. S. (2020). A Mensuração da competitividade nas exportações agropecuárias: uma análise empírica Revista Competitividade e Sustentabilidade, 7(3), 668-687, 2020.

\footnotetext{
${ }^{1}$ Universidade Federal da Grande Dourados - UFGD. Brasil. E-mail: lucas smramos@hotmail.com
} 


\section{INTRODUÇÃO}

Após mais de dois séculos e meio dos primeiros ensaios econômicos que buscavam mensurar competitividade das exportações entre os países, ainda existem muitas discussões sobre. Verter (2016) coloca que ao longo da história, a competitividade vem sendo discutida desde Adam Smith (1776); Ricardo (1817); Heckersher (1919); Ohlin (1933). Em uma abordagem mais moderna destacam-se Leontief (1953); Linder (1961); Vernon (1966); Grubel e Lloyd (1971); Helpman e Krugman (1986); Porter (1990).

O termo competitividade passa por diversas discussões para a sua definição. Uma das abordagens para definir o termo é, como a capacidade de enfrentar a competição e ser bemsucedido no mercado internacional (Naseer et al., 2018). Alguns estudos levam em consideração, para definir o termo, a rentabilidade, a eficiência ou mesmo a produtividade (Lemonaski, 2015).

Na busca para responder questões sobre a competividade, a economia neoclássica, juntamente com a administração estratégica, buscou mensurar a competitividade. A neoclássica se concentra no sucesso do comércio e mede a competitividade com a real taxa de câmbio, índices comparativos de vantagem e exportação ou índices de importação. Já a outra abordagem é medida por vários indicadores de custos, incluindo produtividade e eficiência (Naseer, et al., 2018).

Nesse contexto, a busca por estabelecer uma metodologia com maior eficiência para a análise de competitividade de um setor econômico, terá que levar em consideração a sua localização (a taxa de câmbio pode alterar o resultado), sendo que o custo de um país diverge em muitas áreas dos outros, bem como a produtividade.

Diante disso, este trabalho buscou identificar as metodologias mais usadas para mensurar a competitividade das exportações no mundo, com destaque para Brasil, utilizando-se de uma revisão bibliométrica como metodologia. Existem muitos métodos disponíveis para essa mensuração. E é importante conhecer esses métodos, como estão sendo aplicados e quais os principais estudiosos sobre o tema. Assim, a revisão bibliográfica e a bibliométrica são importantes ferramentas para a análise das publicações sobre o tema.

A competitividade das exportações é um indicador importante na análise do fluxo do comércio internacional, contudo, em estudos empíricos sobre a agricultura, é muitas vezes negligenciada (Jambor, et al., 2018). Com base nisso, os produtos agropecuários foram escolhidos para este estudo, por se tratar de produtos que apesar das novas tecnologias existentes, que envolvem o processo de produção, o seu uso se difere muito entre a produção dos países.

A fim de atender ao objetivo proposto, realizou-se uma pesquisa bibliométrica de caráter exploratório e descritivo. Esse tipo de pesquisa define-se como uma técnica quantitativa e estatística, com o objetivo de busca de indicadores efetivos de atividade acadêmica, decorrentes de publicações sobre a competitividade das exportações. Para Marconi e Lakatos (2001), a pesquisa bibliográfica é o levantamento de toda bibliografia já publicada sobre determinado tema, principalmente, em livros, revistas, entre outros, e tem como objetivo colocar o leitor em contato direto com materiais escritos sobre o assunto.

Foram analisadas duas amostragens para a pesquisa, uma internacional e outra nacional. Para a internacional a busca foi baseada nos periódicos Web Of Science e Scopus. Para a nacional foi utilizado o Google Acadêmico. O período da análise foi de 2014 a 2019, utilizando das palavras-chave: Competitividade, Exportação e Agr*. A base internacional apresentou um total de 622 artigos selecionados, após a filtragem (selecionando artigos que 
analisaram a competitividade e exportação, além de ser adotado uma metodologia para a análise de produtos agropecuários), foram analisados 22 artigos que atenderam ao escopo da pesquisa. Para o nacional, foram encontrados 391 artigos relacionados no período, e destes 29 atenderam ao escopo da pesquisa. Após a filtragem, os artigos foram analisados utilizando o software Excel.

Este artigo é composto por cinco seções, incluindo esta introdução. As seções dois, três e quatro retratam, respectivamente, uma abordagem do comércio internacional, análise dos métodos usados internacionalmente e nacionalmente, e por fim, são apresentadas as considerações finais.

\section{O COMÉRCIO INTERNACIONAL EM UMA ABORDAGEM TEÓRICA}

O comércio internacional é protagonista em diversas discussões econômicas sobre as perspectivas de produção, exportação e importação. Uma das pautas mais proeminentes nessas discussões é com respeito à competitividade das nações. Lafay (1999), define a competitividade como a comparação entre dois ou mais países.

A economia arrisca-se a explicar a competitividade por diversas formas, como Adam Smith (1776), David Ricardo (1817), Balassa (1966), Learmer e Stern (1970), Potter (1991). Estudos esses que buscavam maneiras de mensurar e analisar a competividade das nações e seus ganhos.

Krugman (2001) destaca que a possibilidades de ganhos com o comércio é o que há de mais importante na economia internacional. $O$ autor também menciona que o comércio internacional produz um aumento no produto porque permite que cada país se especialize em produzir o bem no qual possui vantagem comparativa. A economia internacional percorreu um longo caminho até chegar à visão atual de seus conceitos, desde o mercantilismo aos dias atuais.

O Mercantilismo (1500-1800) foi marcado pelas navegações europeias que intensificaram o comércio mundial e a relação entre as nações, principalmente em virtude das explorações das colônias americanas e africanas, aumentando assim o desenvolvimento intercontinental. Contudo, na abordagem mercantilista, o país deveria proteger suas mercadorias, de modo a aumentar seus metais preciosos.

Adam Smith (1776) criticava a abordagem mercantilista que, em sua visão, eles não percebiam o ganho que ambos os países poderiam ter quando houvesse a troca de mercadorias. Adam Smith argumentava que ambos estariam beneficiando, pois, iriam adquirir vantagem pela especialização do outro país em produzir um bem com maior eficiência, assim, se uma nação não possui essa eficiência para a produção, deveria comprar (importar) e comerciar com aquela que tivesse maior eficiência.

Por essa análise, Smith introduziria o conceito chamado de Vantagem Absoluta, com base na ideia de que se um país pode produzir uma unidade de um bem com menos trabalho que outro, diz-se que esse tem uma vantagem absoluta. Com isso, a vantagem absoluta abordada por Smith, ocorre quando cada país se concentra em produzir somente as mercadorias que apresentem melhores condições de fazê-lo (Krugman, Obstfeld, 2001).

Apesar da obra de Smith apresentar uma justificativa plausível, ficavam ainda alguns questionamentos, por exemplo, e se a nação não apresentar vantagem absoluta em nenhum produto ou em vários, como esse país deveria proceder? Com base nessa análise, David Ricardo (1817) apresenta a Vantagem Comparativa. Se esse país não tiver nenhum produto com vantagem absoluta ou tivesse vários, deveria se especializar naquele que tivesse 
vantagem comparativa.

David Ricardo colocava, por exemplo, que países pobres (ou sem tecnologia) para produzir mercadorias com tanta eficiência em que países ricos, deveriam levar em consideração os produtos nos quais houvesse o fator de custo de produção menor (fazer uma comparação entre os produtos, mesmo que de uma maneira negativa). Com isso, o termo que pode ser considerado como ponto-chave na obra de David Ricardo então se dá pelo Custo de Oportunidade.

A obra de David Ricardo dava maior respaldo para a economia internacional, contudo, possuía uma limitação, a teoria fazia a análise focada apenas no trabalho, assim surgiam questionamentos de como o mesmo produto teria diferentes custos em países com o mesmo nível de tecnologia, capital e trabalho. Depois de mais de um século aparece em cena uma explicação razoável para mostrar as diferenças de custo de produção de uma mesma mercadoria em diferentes países (Auxiliadora, et al., 2006).

Com base nessa lacuna surge a teoria de Heckesher-Ohin (HO) afirmando que cada país tende a se especializar e por consequência exportar o bem em que requer os fatores de produção em maior disponibilidade. Assim, o fundamento do trabalho HO é de que as nações fazem a troca de mercadorias porque não podem comercializar esses fatores de produção (Hecksher \& Ohlin, 1991).

A teoria neoclássica de comércio internacional teve os seus fundamentos básicos formulados no modelo de HO. Com base nele é determinada a competitividade pelas vantagens comparativas dos países, no que lhe concerne, suas fontes são dos fatores de produção, capital e trabalho (Carmo, et al., 2014).

Com base nesses percursores foram fundamentados os métodos de análise de competitividade entre as nações. O pressuposto formulado por Balassa (1965), fundamentado na teoria econômica clássica Ricardiana, de que cada país deveria se especializar na commodity de menor desvantagem absoluta, se expressa no índice de Vantagem Comparativa Revelada (IVCR), que possibilita analisar a competitividade a partir das informações passadas dos fluxos comerciais.

Hecksher e Ohlin analisavam as vantagens comparativas geradas em diferentes níveis de estoques segundo os diferentes fatores de produção, aspecto capaz de alterar o valor de produção dos bens. Levando em consideração que países com grau tecnológico mais elevado utilizam diferentes fatores de produção, como área de terra, recursos naturais, mão de obra e capital (Heckscher \& Ohlin; Ohlin, 1991, 1933).

Posteriormente Porter (1993), coloca que os pressupostos em que se baseiam as teorias do comércio internacional, apoiado nas vantagens comparativas ao nível de fatores, são irrealistas em alguns setores. Com isso, surge a análise da competitividade, que representa um conceito dinâmico, que vai além da análise do comércio entre países, em termos da dotação de fatores, preços e custos.

Krugman (1991) desenvolveu a teoria da vantagem competitiva, na qual a competitividade internacional é o resultado da especialização baseada em rendimentos crescentes em vez das vantagens comparativas. A teoria do Comércio Estratégico agrega a teoria convencional $\mathrm{HO}$, ao enfatizar que podem ocorrer mudanças na balança comercial mediante a atuação estratégica em mercados globais imperfeitos. 


\section{ANÁLISE BIBLIOMÉTRICA DA COMPETITIVIDADE: NACIONAL E INTERNACIONAL}

Diante das palavras-chave usadas (Competitividade, Exportação e Agr*, considerando período de 2013 a 2019) e com as bases de dados, foram encontrados 632 artigos, relacionados nas plataformas Web of Science e Scopus. Após a filtragem, retirados os artigos duplicados e os que não se enquadrava no escopo do trabalho (produto ligado à agropecuária), foram selecionados 22 artigos internacionais.

Para as mesmas palavras-chave no Google Acadêmico e mesmo período, foram encontrados 329 documentos. Após a filtragem dos temas dentro do escopo e período, 29 artigos nacionais foram analisados, como mostrado na Tabela 1.

Tabela 1. Publicações nacionais e internacionais, sobre competividade selecionadas por ano.

\begin{tabular}{cccccccc}
\hline ANO & $\mathbf{2 0 1 4}$ & $\mathbf{2 0 1 5}$ & $\mathbf{2 0 1 6}$ & $\mathbf{2 0 1 7}$ & $\mathbf{2 0 1 8}$ & $\mathbf{2 0 1 9}$ & TOTAL \\
\hline $\begin{array}{c}\text { ARTIGOS } \\
\text { INTERNACIONAIS } \\
\text { ARTIGOS NACIONAIS }\end{array}$ & 2 & 3 & 4 & 6 & 6 & 1 & 22 \\
\hline
\end{tabular}

Fonte: Resultado da Pesquisa.

A Tabela 1 mostra uma maior quantidade de publicações sobre o tema nos periódicos nacionais, o ano de 2016 apresenta um valor diferenciado aos demais. Cabe ressaltar que este estudo foi realizado considerando dados até junho de 2019, com isso, poderá haver mais publicações que o apresentado. Posteriormente, foram analisados os autores que mais escreveram sobre competitividade no mundo e no Brasil. O resultado encontrado é apresentado na Tabela 2, em que estão os autores que apresentaram mais de um artigo relacionado a competitividade nos últimos cinco anos.

Tabela 2. Principais autores com publicações na temática.

\begin{tabular}{cccc}
\hline Autor Internacional & $\begin{array}{c}\text { Quantidade de } \\
\text { Publicações }\end{array}$ & Autor Brasileiro & $\begin{array}{c}\text { Quantidade de } \\
\text { Publicações }\end{array}$ \\
\hline BOJNEC & 3 & CORONEL & 10 \\
FERTO & 3 & SILVA R. A & 5 \\
VALENCIANO & 2 & SILVA M. L & 4 \\
BATTISTUZZI & 2 & FRANCK & 4 \\
JAMBOR & 2 & MACEDO & 3 \\
BHATTACHARYA & 2 & CONTE & 3 \\
\hline
\end{tabular}

Fonte: Resultados da Pesquisa.

Como observado na Tabela 2, as publicações internacionais apresentam um número inferior de publicações dos mesmos autores. Cabe ressaltar a especialização por parte de alguns autores brasileiros com 10 e 5 publicações do tema nos últimos 5 anos (ressaltando que só foram analisados a competitividade de produtos da agropecuária). A seguir será apresentado o número de autores por artigos (Figura 1 e 2), é possível observar o número elevado de autores por artigo nas publicações brasileiras. 
Ramos, L. S. (2020). A Mensuração da competitividade nas exportações agropecuárias: uma análise empírica

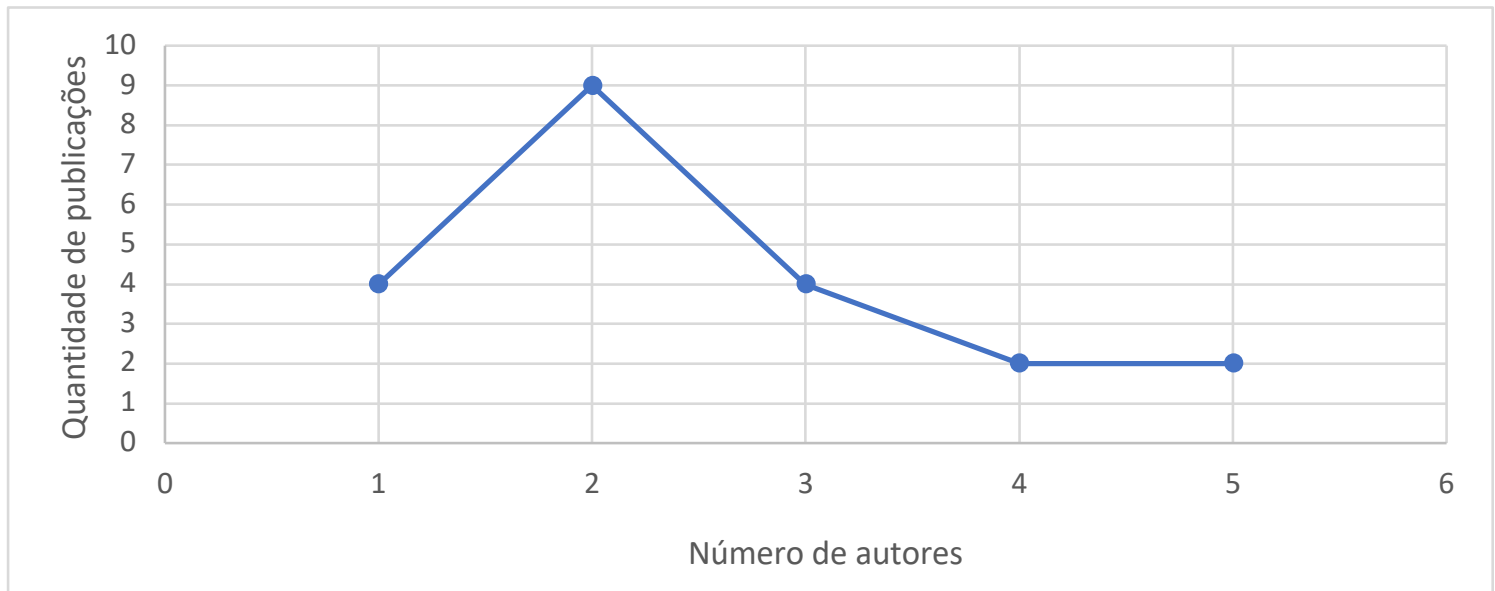

Figura 1- Quantidade de autores por publicação internacional no período de 2014 a 2019.

Fonte: Resultados da Pesquisa.

De acordo com a Figura 1 e possível observar que, para os artigos internacionais há uma concentração no número de artigos com 2 autores. São significativos também os artigos com somente 1 autor.

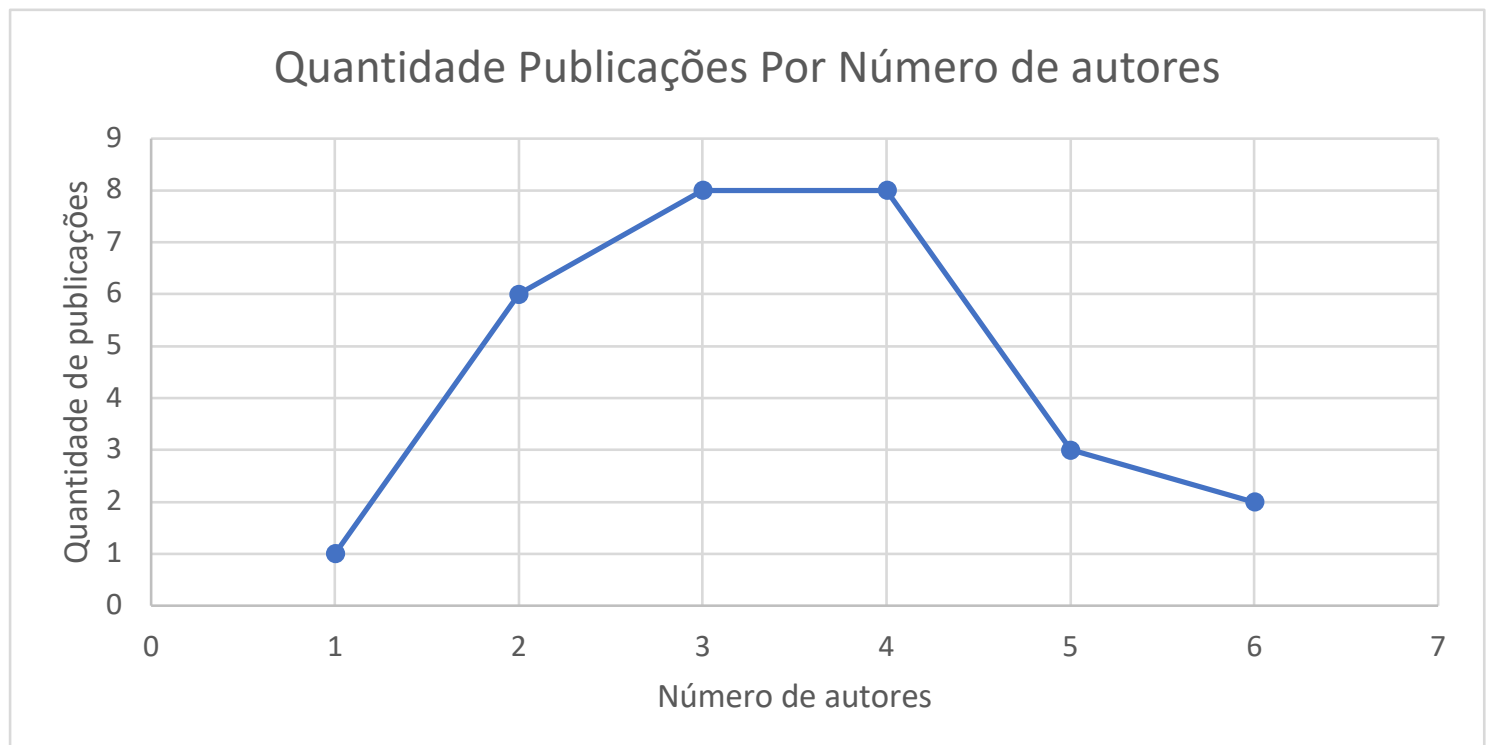

Figura 2 - Quantidade de autores por publicação nacional no período de 2014 a 2019.

Fonte: Resultados da Pesquisa.

Como apresentado nas Figuras 2, as publicações nacionais apresentam um número mais elevado de autores, quando comparado as publicações internacionais. A seguir, apresentam-se os métodos de mensuração de competitividade amplamente utilizado na literatura do mundo e do Brasil (Figura 3 e 4). 


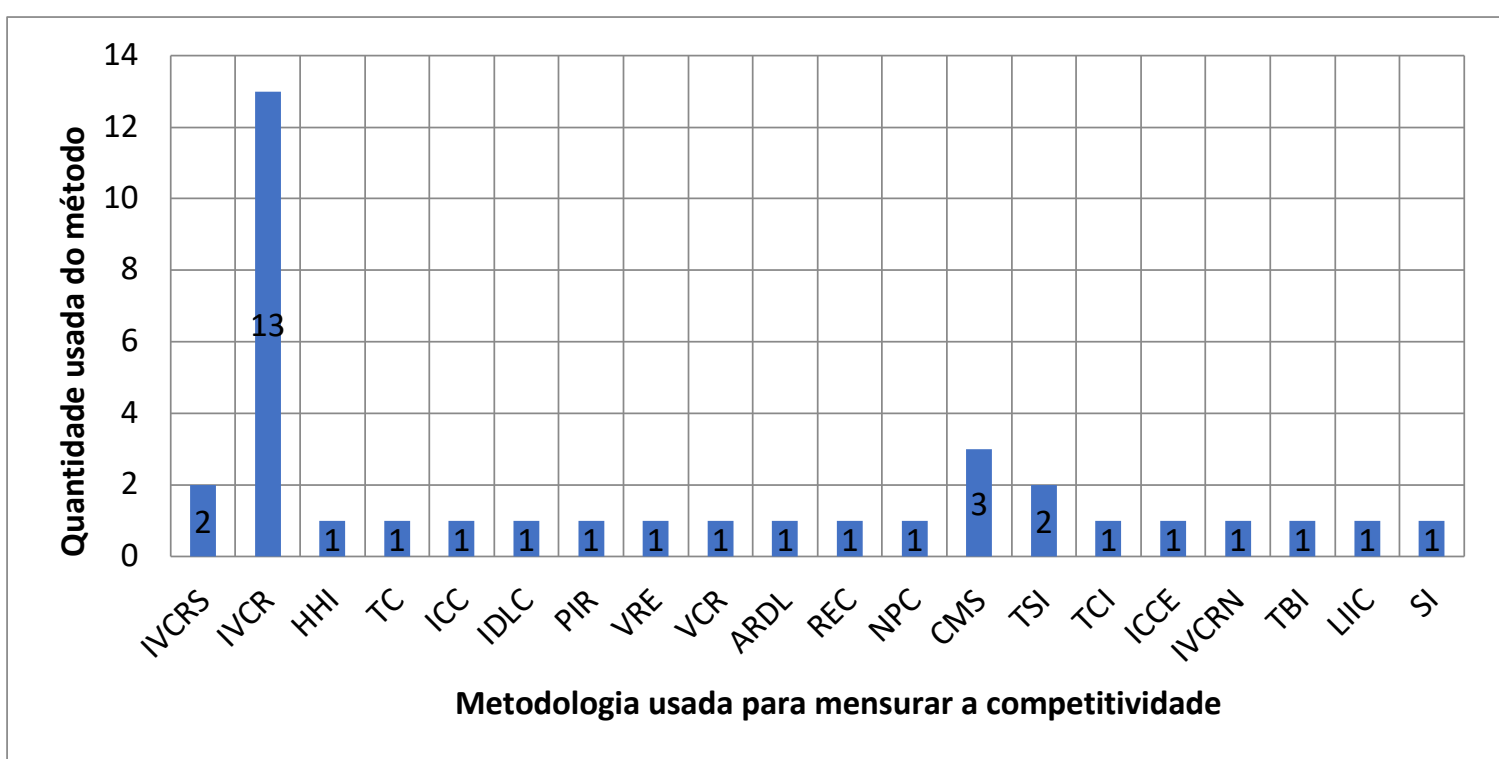

Figura 3 - Métodos usados para analisar a competitividade (internacional) período de 2014 a 2019. Fonte: Resultados da Pesquisa.

Como mostrado na Figura 3, entre os métodos mais comumente utilizados na literatura internacional o Índice de Vantagem Comparativa Revelada (IVCR) é o mais representativo, sendo usado em 13 dos 22 artigos analisados. Ademais, dois índices oriundos do IVCR também são utilizados para análise (IVCRN e IVCRS). O método Constant Market Share (CMS) foi o segundo mais usado como método de mensuração de competitividade. $A$ Figura 4 apresenta os métodos usados no Brasil.

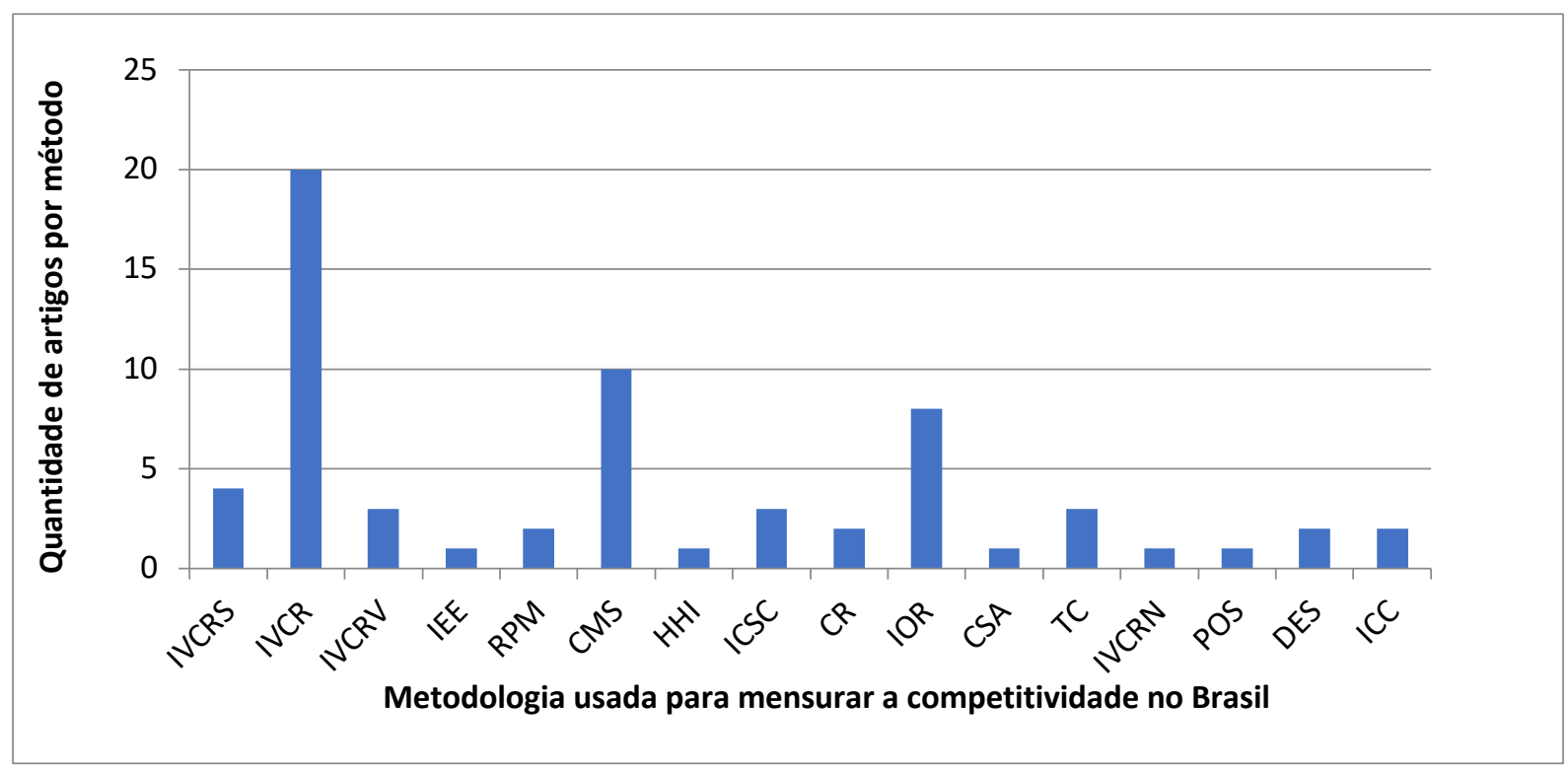

Figura 4 - Métodos de mensuração de competitividade no Brasil, no período de 2014 a 2019. Fonte: Resultados da Pesquisa.

Como na literatura internacional, os métodos mais utilizados no Brasil também são o IVCR e CMS. Contudo, no caso brasileiro, o CMS foi utilizado em uma quantidade mais significativa de artigos. Ainda pode-se notar o uso Índice de Orientação Regional - IOR, como um método amplamente usado também. 
Ramos, L. S. (2020). A Mensuração da competitividade nas exportações agropecuárias: uma análise empírica

Após a análise bibliométrica é importante conhecer os estudos realizados e os resultados obtidos a partir destes. Essa análise é realizada na próxima seção.

\section{MÉTODOS DE ANÁLISE: UMA ABORDAGEM EMPÍRICA INTERNACIONAL}

Diversas são as metodologias que buscam analisar a competividade entre os países. A seguir será apresentada uma descrição Bibliográfica dos estudos e metodologias encontradas relacionado à exportação de produtos agropecuários a partir da busca nos principais periódicos no período de 2014 a junho de 2019.

O método Índice de Vantagem Comparativa Revelada (IVCR) foi usado para investigar a competitividade das exportações agroalimentares dos países da União Europeia (EU-27) no mercado mundial, ao longo dos anos de 2000 a 2011. Conclui-se que a maior parte os membros mais antigos (UE-15), registou um maior número de produtos agroalimentares com uma duração mais longa das vantagens comparativas reveladas, em comparação aos novos Estados-Membros da UE-12 (Bojnec \& Ferto, 2015).

Em outro estudo Bojnec e Ferto (2016), fizeram a análise sobre a UE-27, com IVCR para fornecer evidências sobre a competitividade das exportações de frutas e vegetais entre 2000 a 2011 dos países membros nos mercados globais. Os autores concluíram que a maioria dos países membros da UE-27 experimentou desvantagens comparativas nos produtos de frutas e vegetais nos mercados globais (Bojnec \& Ferto, 2016).

Ainda na Europa, mas agora utilizando os métodos Trade Coverage Index (TC) e o método Herfindal-Hirschman index $(\mathrm{HHI})$, foi analisado o comércio exterior Checo de leite e produtos lácteos. A análise abrange o período entre 1999 e 2015 e é interpretada no contexto das mudanças do ambiente de negócios que ocorreram nas duas últimas décadas, particularmente em relação à entrada da República Checa na União Europeia. A República Tcheca revelou saldo positivo no comércio de leite e derivados, bem como valores favoráveis do índice TC (ZDRÁHAL; BECVAROVA, 2018).

Com o objetivo mensurar a competitividade interna de leite e seus derivados com os países da UE-27, no período de 2007 a 2013 na República Tcheca. Dusan, et al (2015), utilizaram os métodos IVCR; o índice de crescimento da competitividade ICC; o índice de desempenho comercial líquido (IDCL); o indicador de penetração de importações relativas (PIR); o indicador de vantagens relativas de exportação (VRE); e o indicador de vantagens comerciais relativas (VCR). A pesquisa dos parâmetros de competitividade do comércio exterior do grupo agregado Leite mostrou que a República Eslovaca tem uma vantagem comparativa entre os países da UE-27 na commodity leite e nata. Em todas as outras commodities monitoradas, foi determinada uma desvantagem comparativa.

O Índice de Balassa (IB) foi usado para analisar a competitividade das exportações de produtores globais de cacau do período de 1992 a 2015. Os resultados sugerem que o comércio global de cacau é altamente concentrado, com Gana e Indonésia obtendo as maiores vantagens comparativas em 1992-2015. No entanto, os testes de duração e estabilidade indicam que as vantagens comerciais diminuíram para a maioria dos países (Jambor et al., 2018).

Para examinar os determinantes da competitividade das exportações das principais frutas da Índia de 1971 a 2012, foi usado o modelo Autoregressive Distribudes Lag (ARDL) e IVCR. Como resultado, encontrou-se uma relação de longo prazo entre a competitividade das frutas para exportação e seus principais determinantes. O Produto Interno Bruto (PIB) per capita dos principais países importadores de frutas, preço interno de frutas, 
investimento no setor agrícola e taxa de câmbio real efetiva influenciam significativamente a competitividade das exportações de frutas frescas na Índia (Bhattacharya, 2018).

Também na Índia, foi usado o método Relative Export Competitiveness (REC), que deriva a competitividade relativa das exportações (agrícolas do arroz, trigo, algodão e açúcar) contra a participação da Índia nas exportações agrícolas mundiais e as exportações mundiais de 1981 a 2012. Concluiu-se, com o estudo que as exportações da Índia de todas as quatro commodities se tornaram relativamente competitivas ao longo do tempo, mas estas não foram tão competitivas quanto as principais exportadoras emergentes das quatro commodities (Narayan \& Bhattacharya, 2019).

A partir dos métodos de IVCR, Coeficiente de Proteção Nominal (NPC) e Índice de Vantagem Comparativa Revelada Simétrica (IVCRS), Vanitha, Kumari e Singh (2014), determinaram a competitividade das exportações, a vantagem comparativa nas exportações e a participação de mercado de vegetais frescos selecionados cultivados na Índia. Os resultados mostraram que a Índia tem uma vantagem comparativa na exportação de cebola e ervilha em comparação com outros vegetais. Tomate, cebola e batata formaram a maior parcela de hortaliças exportadas, constituindo $45 \%$ da área total cultivada com hortaliças e $50 \%$ da produção total de hortaliças na Índia.

Também na Índia foi estudada por Alpesh, et al (2017) a competitividade com o IVCR, para a análise de serviços de agricultura estrangeira dos anos de 2010 a 2014. Os resultados do Índice indicam que a Índia tem uma vantagem comparativa notavelmente alta e especialização em arroz, amendoim, legumes, cebola fresca, suco fresco, uvas frescas e sementes de frutas e vegetais e especialização sobre as exportações agrícolas mundiais. Além disso, os indianos também desenvolveram vantagem comparativa em produtos processados, como pepinos, vegetais secos e conservados (Alpesh, et al., 2017).

O método do Constant Market Share (CMS) foi usado para quantificar o efeito da dinâmica de produção no mercado interno e a competitividade da carne bovina ininterrupta nos EUA, e também foi usado o Índice de Vantagem de Exportação Relativa (REA) dos anos de 2003 a 2012. No estudo identificou-se um caminho de crescimento estável, sem apresentar uma vantagem comparativa. Da mesma forma, a dinâmica gerou um aumento substancial na participação de mercado nos EUA, que é gerada por um crescimento no mercado-alvo, e aumentou a concorrência dentro do setor de carnes no México (Armando, et al., 2015).

O método de CMS foi usado também para a análise empírica das vantagens comparativas e da complementaridade do comércio agrícola entre a China e os Estados Unidos, em termos de seis produtos agrícolas principais, desde 1997 a 2018. Também foram usadas as metodologias: Trade Combining Density Index (TCD), the Export Similarity Index (SI) and the Trade Complementarity Index (TCI). Os resultados indicam que os agro-produtos exportados da China e dos Estados Unidos refletem as características da dotação de recursos de cada país; a competitividade do agro-produto da China diminuiu após a sua adesão à OMC, enquanto a estrutura de agro-exportação do país foi melhorada (Shuai; Wang, 2018).

Valenciano e Battistuzzi (2015) utilizaram a metodologia do Índice Competitividade do Comércio Exterior da (ICCE) de 2007 a 2012, para evidenciar as mudanças que estão sendo experimentadas no comércio global de peras. Seu objetivo foi saber se os processos de integração entre os países estão afetando sua competitividade no comércio internacional. Os autores concluíram que a competitividade do comércio global em peras é regional e não global, resultando em ser competitiva apenas em mercados próximos sujeitos a acordos comerciais. 
Para medir a competitividade agrícola do Vietnã de 1997 a 2014, Hoang, et al (2017) utilizaram os métodos IVCR e Índice de Vantagem Comparativa Revelada Neutral (IVCRN). Os resultados mostram que o Vietnã, em geral, alcança forte competitividade nos setores de cultivos e pesca, ao mesmo tempo, em que tem fraca competitividade nos setores de pecuária e alimentos processados. Além disso, o país tem o padrão convergente de competitividade agrícola com a alta estabilidade de fortes setores competitivos e não competitivos. A estratégia de exportação agrícola e o padrão de competitividade do país baseiam-se nos produtos agrícolas tradicionais e intensivos em recursos naturais, com uma ligeira melhoria ao longo do tempo.

O setor de tomate processado em Portugal foi analisado através do indicador IVCR para medir a competitividade internacional entre 1981 a 2013. Durante o período 2011-13, observou-se uma ligeira melhoria nos indicadores de competitividade. O preço mundial é uma variável importante para as exportações portuguesas de pasta de tomate. Para a pasta de tomate, destaca-se o comércio interindustrial e, para outros produtos de tomate, observa-se um comércio intrasetorial horizontal (Oliveira, et al., 2017).

Para a avaliação da competitividade comercial no setor europeu de produtos alimentares, Balogh e Jámbor (2018) usaram o IVCR para a análise dos principais produtores europeus de queijo entre 1990 e 2013. Os resultados sugerem, em relação às vantagens comparativas, que os Países Baixos, Dinamarca e Chipre foram os que mais se destacaram no queijo da UE. No entanto, a análise dos sobreviventes revelou que as vantagens comparativas eram muito estáveis para os países selecionados. A estabilidade geral do comércio de queijos da UE seguia a uma tendência decrescente.

A Costa do Marfim é a maior produtora e exportadora de grãos de cacau no mundo. Neste contexto, Verter (2016) buscou avaliar o desempenho das exportações do país e determinar alguns impulsionadores externos do comércio de exportação no período de 1980 a 2013, utilizando o Índice de Especialização Comercial (TSI). Observou-se que, embora o desempenho do país tenha flutuado ligeiramente ao longo dos anos, ele permanece competitivo e tem testemunhado uma direção positiva quase todos os anos.

Com base no IVCR, Esquivas (2017) realizou a análise das mudanças nos padrões de comércio agrícola de Java Oriental, na Indonésia, em comparação com os seis principais países exportadores da Associação de Nações do Sudeste Asiático - ASEAN, dos anos de 2007 a 2013, nas 545 commodities que compõem o setor agrícola. A especialização por vantagens parece ser uma característica importante do agronegócio para os países da ASEAN, porque a maior parte do crescimento das exportações está sob essas commodities competitivas. Pouca diversificação em relação a novos produtos foi encontrada nos últimos anos. Os ganhos parecem ser maiores que as perdas devido à abertura internacional, enquanto as oportunidades dentro da região não foram exploradas.

Para determinar o nível de competitividade das exportações de mel na Turquia e compará-lo com o dos países dos Balcãs, para os períodos de 2001-2015, Terin, et al (2018) utilizaram o IVCR e o Trade Balance Index (TBI). Os resultados revelaram que os escores médios de RCA e TBI para a Turquia foram de 1,86 e 0,86, respectivamente. Os resultados mostram que, apesar da fraca vantagem comparativa, a Turquia ainda é um país exportador líquido de mel. De acordo com a média dos escores RCA, Bulgária, Romênia e Sérvia têm forte vantagem comparativa, Croácia e Grécia têm baixa vantagem comparativa, e República da Macedônia tem fraca vantagem comparativa na exportação de mel enquanto Albânia, Bósnia e Herzegovina e Eslovênia não têm vantagem comparativa na exportação de mel.

De modo a proteger certos setores, a Rússia introduziu algumas novas medidas de 
proteção para os produtos agrícolas da UE, a fim de medir o nível de competitividade dos produtos lácteos da Lituânia no comércio com a Rússia e em mercados alternativos foi realizada uma pesquisa com base no índice de competitividade internacional na região específica (local) (LIIC) de 2010 a 2015. A investigação encontrou um aumento na competitividade da exportação de produtos lácteos nos países da UE-28 e fora dos mercados da UE. Os resultados diferiram pelo nível de competitividade entre dois grupos de países. No período de análise, o índice LIIC foi maior no primeiro grupo do que no segundo grupo de países da UE (Stankaityte, 2016).

Valenciano, et al (2017) realizaram uma análise quantitativa da competitividade das exportações de pera da África do Sul (SA) para o mercado da UE contra países concorrentes como Argentina, Chile e China, com base no CMS. Esta análise dividiu-se em dois períodos 2002-2007 e 2008-2013 - para testar se a crise econômica e financeira global de 2007-2008 teve um impacto significativo no comércio de pera sul-africana. Os resultados mostram que, antes da crise econômica e financeira global, o efeito estrutural das exportações de SA contribuiu mais para o crescimento das vendas de peras para a UE, e um efeito geral de competitividade contribuiu em menor escala. A partir de 2007, a competitividade especificada foi o principal contribuinte para o crescimento das exportações de peras SA.

Com o objetivo de fornecer informações sobre a competitividade das exportações de produtos cárneos dos países membros da UE-27 nos mercados globais, Bojnec e Ferto (2014) utilizaram o IVCR para os anos de 2000 a 2011. Com exceção de alguns produtos do nicho da carne, um maior número de Estados-Membros da UE-27 registrou-se desvantagens comparativas nos mercados mundiais. As vantagens comparativas reveladas nos mercados globais são as mais robustas para a Irlanda, Espanha, Países Baixos, França, Bélgica, Dinamarca, Polónia, Chipre e Hungria. O IVCR e suas taxas de sobrevivência diferem entre os grupos de produtos cárneos (Bojnec \& Ferto, 2014).

Para examinar a competitividade da indústria de mandarim para os 15 líderes do mundo, foram analisados exportadores de tangerina usando IVCRS. Os resultados mostraram que os padrões de IVCRS variam entre os países selecionados e apenas cinco países, isto é, Marrocos, Espanha, Paquistão, Turquia e Peru têm uma vantagem comparativa nas exportações de mandarim, outros países têm uma desvantagem comparativa. A maior variação do índice foi observada no Paquistão, que dá uma boa indicação do status do país no desenvolvimento de sua indústria. Para o Paquistão, é necessário explorar ainda mais essa vantagem comparativa e aumentar as receitas de exportação (Abbas \& Waheed, 2017).

\section{COMPETITIVIDADE E MÉTODOS DE ANÁLISE: UMA ABORDAGEM EMPÍRICA NACIONAL}

Com o objetivo de analisar o desempenho e a competitividade das exportações do Brasil e da Argentina no mercado internacional de mate, durante o período de 1997 a 2011, Schirigatti, et al (2018) utilizaram o método do IVCRS. Os resultados obtidos no período integral mostraram que, tanto o mate brasileiro quanto o argentino apresentaram produtos que possuem vantagem comparativa dentro de mercados com demanda crescente.

A competitividade das exportações de soja em grão no período de 2001 a 2012, foi estudada por Coronel, et al (2014), utilizando os modelos do CMS bem como dos IVCR, IOR, Índices de Cobertura (IC) e de Frequência (IF), a fim de quantificar os efeitos das principais barreiras não tarifárias impostas pelos principais mercados de destino, China e União Europeia. Os resultados indicaram que o Rio Grande do Sul apresentou Vantagens 
Comparativas Reveladas para a soja em grão em todo o período analisado.

Com base no Índice de Vantagem Comparativa Revelada de Vollrath (IVCRV) foi mensurada a competitividade existente entre os Estados do Ceará e Rio Grande do Norte, na exportação de melão, entre os anos de 1997 a 2014. Os resultados mostram que ao final da década de 1997, o Estado do Rio Grande do Norte apresentava um alto índice de competitividade na exportação do melão, sendo praticamente o único exportador neste período. Contudo, a partir dos anos 2000, o Ceará avança na sua participação no mercado produtor e exportador, chegando em meados da década a ultrapassar o Rio Grande do Norte (Santos \& Santos, 2016).

Franck, et al (2016), com o objetivo de analisar a competitividade das exportações gaúchas do agronegócio, especificamente de soja, fumo e carnes, no período de 1999 a 2012, utilizaram os métodos do IVCR e o Índice de Esforço Exportador (IEE). Os resultados indicam que as exportações gaúchas de soja, carnes e fumos apresentaram grande relevância na composição da geração de renda do estado, com o IEE indicando que um grau de abertura comercial do estado elevado, pois quase $50 \%$ do PIB era composto pelas exportações dos complexos analisados.

Para analisar a competitividade do Brasil no mercado internacional de celulose, comparando-o com a competitividade de seus principais concorrentes no mercado mundial no período de 2000 a 2006, Carvalho, Silva e Soares (2015) utilizaram as metodologias IVCR e os índices de posição relativa no mercado (RPM). Os resultados indicaram que o Brasil se classificou entre os três países mais competitivos no mercado global de celulose de madeira.

Também para o cálculo da competitividade de celulose, agora no período de 1990 e 2013, Olvão, et al (2015), utilizaram o IVCR, IVCRS e índice de contribuição ao saldo comercial (ICSC) para o Brasil e para 12 países maiores produtores mundiais de papel e celulose. Também foi utilizado o HHI para identificar a concentração da produção e dos mercados para os quais o país exporta e o modelo de CMS para decompor e explicar o padrão das exportações brasileiras de papel e celulose. Os resultados do VCR e do VCRS indicaram alta competitividade em celulose e baixa competitividade em papel. Os resultados do modelo de CMS confirmaram a alta competitividade em celulose e baixa competitividade em papel.

Para analisar a competitividade das exportações brasileiras no mercado mundial de milho, entre 2000 e 2014, em comparação ao maior produtor e exportador mundial, os Estados Unidos da América (EUA), e o grau de concentração das exportações desses países, utilizou-se da metodologia IVCR e da Razão de Concentração (CR). Os resultados revelaram que o Brasil apresentou vantagens comparativas para milho para semeadura, em 2000, e para milho, exceto para semeadura, em 2014. Já os EUA apresentaram vantagens para ambos os produtos e nos dois períodos de análise (Arruda, et al., 2016).

Em outro estudo, com o objetivo de analisar a competitividade das exportações de fumo no período de 2001 a 2012, foi usado o modelo CMS bem como o IVCR e o IOR. Os dados referem-se às exportações gaúchas de fumo e as exportações e importações mundiais da União Europeia e da China, durante o período de 2001 a 2012. Os resultados indicaram que o Rio Grande do Sul apresentou Vantagens Comparativas Reveladas para o fumo em todo o período analisado. No que tange às fontes de crescimento, o efeito competitividade foi o que mais colaborou para as exportações e o efeito crescimento do comércio mundial foi preponderante. No que tange à orientação regional, a exportação do fumo está orientada com maior intensidade para a União Europeia (Fries, et al., 2014).

Para analisar a competitividade das exportações gaúchas, especificamente de soja 
em grão e fumo para o mercado chinês, no período de 1999 a 2013, Silva, et al (2015), utilizaram os métodos para o cálculo de indicadores de competitividade do comércio internacional: (IOR) e Índice de Contribuição do Saldo Comercial (ICSC). Os resultados indicam que as exportações de soja e fumo do Rio Grande do Sul são direcionadas à China, bem como, se verificou tendência a exportar mais para esse destino.

Em busca de analisar a competitividade das exportações brasileiras de cacau para a Argentina e Estados Unidos, no período entre 1999 e 2015, Franck, et al (2015) utilizaram os indicadores de IOR e o IVCR. Os resultados indicaram que a Argentina é um importante mercado consumidor do cacau brasileiro, pois essas exportações estão orientadas ao longo do período em questão, além de representarem uma oportunidade de crescimento das relações entre ambos os países. Contudo, para o mercado norte-americano, as exportações brasileiras de cacau foram pouco orientadas.

Com o objetivo de analisar a competitividade entre Brasil e Argentina nas exportações de carne bovina no mercado mundial, no período 2006 a 2013, usou-se como metodologia o CMS. A partir do estudo realizado por Freitas, et al ((2014), os resultados mostraram, para o primeiro período de análise (anos de 2006 a 2009), que cresceram as exportações brasileiras para quase todos os países. Já a Argentina exportou menos para o Reino Unido, Rússia e Espanha, porém, teve crescimento significativo nas exportações para os demais países. O segundo período (anos de 2010 a 2013) indicou um grande crescimento das exportações brasileiras de carne bovina, mas perdeu mercado para a Rússia.

Vicensotti, et al (2019) realizaram um estudo com a finalidade de verificar a competitividade da carne bovina brasileira no cenário internacional e identificar quais eram os fatores que a afetaram no período ente 1994 a 2015. Para tanto, calculou-se os indicadores de competitividade, Coeficiente de Exportação, Market Share e IVCR. Os resultados alcançados mostram que o Brasil tem superado algumas fraquezas e se encontra numa posição favorável em relação ao comércio internacional de carne.

Para analisar a competitividade das exportações brasileiras no mercado mundial do algodão, entre 2000 a 2017, em comparação ao sexto maior produtor e quarto maior exportador mundial, a Austrália, Coronel e Copetti (2019), utilizaram as metodologias IVCRS, CR e IOR. Os resultados revelaram que tanto o Brasil quanto a Austrália apresentaram vantagens comparativas para o algodão a partir de 2001. Em relação à $C R$, o Brasil apresentou concentração e a Austrália desconcentração das exportações. O IOR indicou orientação das exportações de algodão do Brasil à Indonésia, ao Vietnã e à Turquia.

Para analisar os fatores que afetaram as flutuações das exportações da manga brasileira para os principais mercados importadores, utilizou-se o método CMS, a fim de se observar a importância dos efeitos de competitividade, destino, e crescimento do comércio mundial sobre as mudanças das exportações brasileiras de manga, no período em análise. Entre os resultados encontrados, constatou-se que o efeito competitividade representou a maior parcela do crescimento efetivo das exportações brasileiras, ou seja, o país melhorou sua competitividade dentre os demais países exportadores (Souza et al., 2016).

Com o objetivo de analisar o panorama do mercado internacional de feijões e a competitividade do setor de exportação da cadeia exportadora de feijões brasileira, Almeida, et al (2016) utilizaram o método Commodity System Approach - CSA. Os resultados demonstram que as questões macroeconômicas influenciaram negativamente o fator ambiente institucional no setor de exportação, a concorrência, o câmbio, foram os fatores de maior impacto. As questões sanitárias e fitossanitárias possuem abordagem muito relacionada à análise de risco considerando produto, origem, quantidade e avaliação de 
Ramos, L. S. (2020). A Mensuração da competitividade nas exportações agropecuárias: uma análise empírica

equivalência de sistemas sanitários, sendo esses fatores não controláveis pela firma.

Para analisar a inserção do tabaco sulista no comércio internacional nos anos de 1997 a 2014, foi utilizado o IVCR para observar o comportamento da produção do estado no comércio internacional. Os resultados mostram que a região sul apresenta ligeira vantagem relativa nas exportações de tabaco ao longo dos anos considerados. A competitividade revelada mostrou-se positiva, porém, apresenta vantagem de maior magnitude a partir de 2005 (Sá Barreto \& Novais, 2016).

Para avaliar a competitividade das cooperativas paranaenses frente ao setor cooperativista brasileiro, Teodoro (2017) utilizou como método o IVCR, que avalia os valores das exportações. Evidenciou-se que as cooperativas do estado do Paraná, ao serem comparadas com o setor brasileiro, possuem maiores vantagens comparativas e, portanto, são mais competitivas internacionalmente (Teodoro, 2017).

Para analisar a competitividade e desempenho das exportações de melão pelo Brasil frente aos seus principais concorrentes no período de 2001 a 2012, Rodrigues e Aredes (2017), utilizaram as metodologias CMS e IVCR. De acordo com os resultados, as taxas de crescimento anual da receita com a exportação brasileira com melões frescos superaram a média mundial em três dos quatro períodos estudados, no primeiro 2001-2003, no segundo 2004-2006 e no quarto 2010-2012. O efeito competitividade foi o fator determinante para o bom desempenho dos embarques, seguido pelo efeito comércio mundial.

O trabalho de Macedo e Soares (2015), avaliaram o desempenho das exportações de castanha de caju do Brasil e dos seus principais concorrentes no mercado internacional, de 2007 a 2011, por meio dos indicadores de posição relativa do mercado, IVCR e CMS. Os resultados obtidos indicaram que o Brasil e seus principais concorrentes no mercado internacional perderam posição relativa no mercado, exceto a Costa do Marfim. O país com maior vantagem comparativa revelada foi a Costa do Marfim. O crescimento do comércio mundial contribuiu em maior percentual para o crescimento das exportações de castanha de caju dos países analisados, exceto para a Costa do Marfim onde o efeito competitividade superou o crescimento do comércio mundial. E o efeito destino das exportações foi relevante para explicar o crescimento das exportações principalmente do Brasil.

Para analisar o grau de competitividade das exportações da commodity soja nos estados do Mato Grosso e Bahia, no período de 2008 a 2014, foram utilizados os IVCR, IVCRS e IVCRV, além dos índices de TC, Contribuição ao Saldo Comercial e Comércio Intraindústria. Os resultados evidenciam a existência de vantagem comparativa revelada para a soja no estado mato-grossense em todo o período supracitado. Em relação à Bahia, a soja se mostrou competitivo em apenas alguns dos anos analisados. Em ambos os estados, porém, constatou-se que a produção e exportação de soja tem sido relevante para o saldo positivo da balança comercial (Amaral \& Macedo, 2015).

Com o objetivo de analisar a competitividade das exportações brasileiras no mercado mundial do açúcar, entre 2000 e 2016, Fries, et al, (2018) utilizaram as metodologias IVCR e CR. Os resultados revelaram que tanto o Brasil apresenta vantagens comparativas para o açúcar refinado quanto para o açúcar em bruto no período analisado. Em relação à $C R$, o Brasil revelou desconcentração das exportações em ambos os produtos.

Com o objetivo de avaliar a competitividade das exportações de couros e peles dos estados nordestinos, considerando o período de 2002 a 2016, foram utilizados os índices IVCR, IVCRV e o IVCRN. Os resultados indicaram que, dentre os estados nordestinos que comercializam couros e peles com o mercado internacional, somente o estado do Ceará registrou vantagem comparativa desse segmento, em relação ao Brasil, para todo o período 
analisado, sendo confirmado pelos três índices determinados, salvo para o IVCRN para o ano de 2002 (Santos et al., 2017).

O estudo de Pires, et al (2016), analisou o desempenho das exportações de uvas, no período de 2005 a 2014, da região do Vale do São Francisco comparando-a à produção das regiões Sul e Sudeste do Brasil. Para analisar a competitividade das exportações de uva foram utilizados os indicadores de competitividade: IVCR, (TC), Índice de Contribuição ao Saldo Comercial (ICSC) e a Posição Relativa de Mercado (PRM). Os resultados indicam que, para o período analisado, o Vale do São Francisco possui maior competitividade no mercado exportador de uvas no Brasil, dentre as regiões produtoras do país, embora o Sul e o Sudeste destaquem-se no volume total produzido.

Para analisar a competitividade e a inserção das exportações do melão brasileiro, a partir da análise dos dois principais estados produtores, Ceará e Rio Grande do Norte, durante o período de 1993 a 2013, utilizou-se o método CMS. Esta metodologia permite analisar a inserção de países/regiões no comércio internacional e as fontes de crescimento das exportações separando em três componentes: crescimento global, expansão dos mercados de destino e competitividade. Os resultados indicam que o crescimento efetivo das exportações do melão cearense foi determinado pela maior competitividade. Já no caso potiguar, apesar do fator competitividade ter tido importância em alguns períodos, o crescimento do comércio mundial foi uma das principais fontes de crescimento efetivo (Penha \& Alves, 2019).

Para verificar o grau de competitividade das exportações de castanha de caju brasileira em relação aos principais produtores desse produto e o efeito da crise internacional de 2008 sobre a variação das exportações brasileiras da commodity, Janaina, et al (2017) utilizaram os indicadores de IVCR, de posição relativa (POS) e de desempenho (DES) para o período 2000-2011. O modelo CMS foi utilizado para o período 2003-11, com a avaliação de quatro subperíodos: 2003-2005, 2005-2007, 2007-2009 e 2009-2011. A análise dos resultados mostrou que o Brasil vem perdendo espaço no mercado de castanha de caju, e esse mau desempenho pode ser explicado pela perda de mercado, especialmente para a castanha vietnamita, e pela diminuição da competitividade do produto no mercado internacional.

Com o objetivo de analisar a competitividade das exportações de carne de frango do Rio Grande do Sul, quando comparadas com as exportações de outros países, no período de 1997 a 2013, Lazaretti, et al (2018), utilizaram o IVCR e indicadores de concentração de comércio, como o de Gini-Hirchman, e de caracterização do comércio (intra-setor ou intersetor). O estudo confirmou que as exportações gaúchas são competitivas. As exportações do Rio Grande do Sul para a Arábia Saudita possuem vantagem comparativa quando considerado o saldo do comércio. A pauta exportadora do estado é concentrada em poucos destinos, enquanto as importações são diversificadas.

Para atingir o objetivo de analisar a competitividade do mercado exportador brasileiro de café, em relação à Alemanha e aos Estados Unidos, foram usados os índices de Orientação Regional (IOR) e de IVCR, para o período de 2000 a 2014. Os resultados indicaram que as exportações brasileiras de café foram orientadas para a Alemanha, em todo o período, e para os Estados Unidos, a partir de 2006. Ressalta-se que estas orientações são crescentes para ambas as regiões. Porém, o mercado alemão é mais representativo. Além disso, o país apresenta vantagens comparativas na sua exportação, porém, estas são decrescentes devido ao crescimento das exportações de café de outras regiões (Franck et al., 2016). 
Para analisar a competitividade das exportações brasileiras de carne suína no período de 1999 a 2016, Favaretto, et al (2018) utilizaram os indicadores de competitividade do comércio internacional: IVCR, IOR e TC. O Índice de Vantagem Comparativa Revelada mostrou que as exportações brasileiras apresentaram vantagem comparativa em todo o período analisado, sempre com valor maior que a unidade, e o IOR indicou que as exportações estão orientadas para a Rússia, Singapura e Hong Kong. Na análise da taxa de cobertura, fica evidente a superioridade das exportações em relação às importações de carne suína. Esses índices corroboram para a conclusão de que a carne suína brasileira é competitiva frente ao mercado internacional.

Com o objetivo de analisar a competitividade do etanol produzido no Brasil em comparação com a produção dos Estados Unidos, da França e da Holanda, foi utilizado o Indicador de Desempenho das Exportações (DES), o Índice de competição (IC) e o Índice de Vantagem Comparativa Revelada, com dados relativos ao período de 1999 a 2016. Os resultados mostraram que as exportações brasileiras de etanol possuem capacidade para aumentar a sua participação no mercado mundial do produto, além de possuir vantagens comparativas em relação aos demais países (Franck et al., 2016).

\section{CONSIDERAÇÕES FINAIS}

Com base na pesquisa realizada, percebeu-se que as literaturas do mundo para mensurar a competitividade internacional e os métodos aplicados no Brasil seguem das mesmas ferramentas. Entretanto, foi possível diagnosticar, no caso brasileiro, o uso de mais de uma ferramenta para análise do mesmo objeto, enquanto na literatura mundial isso ocorre com menos frequência.

Quanto aos autores, no caso brasileiro, percebeu-se que há um número mais expressivo de autores por artigos quando comparado com a literatura internacional. Assim como um maior número de autores com mais publicações sobre o assunto, podendo considerar uma especialização na área.

Os métodos de análise mais amplamente utilizados foram o Índice de Vantagem Comparativa Revelada (IVCR) e seus derivados (IVCRN e IVCRS), Constant Market Share (CMS) e Índice de Orientação Regional. O IVCR e CMS, apareceram na maioria dos estudos em quantidade tanto nos artigos nacionais quanto nos internacionais. Foi observado a quantidade superior das metodologias utilizada pela literatura internacional comparada a nacional.

Como limitação para o estudo destaca-se o entendimento do conceito de competitividade, sendo esse, uma sugestão para trabalhos futuros, de como cada área do conhecimento e setor entende o que é competitividade, e o que é ser competitivo.

\section{REFERÊNCIAS}

Abbas, A. W. (2017) "Trade Competitiveness of Pakistan: Evidence From The Revealed Comparative Advantage Approach", Competitiveness Review: An International Business Journal, Vol. 27 Issue: 5, Pp.462-475, Https://Doi.Org/10.1108/CR-12-2015-0092

Almeida, P. R. V. Wander, A. E Figueredo, R. S; (2016). Panorama do Mercado Internacional De Feijões: Análise Dos Principais Players Mundiais Com A Competitividade Do Setor De Exportações Brasileira. Revista Gestão, Inovação E Negócios. 2016

Armando, J., Flores, R., Liliana, M., \& Arce, C. (2015). La competitividad de la carne fresca de res 
Ramos, L. S. (2020). A Mensuração da competitividade nas exportações agropecuárias: uma análise empírica

mexicana en el mercado estadounidense Competitiveness of fresh Mexican beef in the U.S. market. 16, 134-149.

Amaral, G. V., \& Macedo, R. D. (2015). Análise de Competitividade Para os Estados da Bahia E Do Mato Grosso Entre os Anos de 2008 E 2014. 456-474.

Arêdes A. L, Rodrigues, J. S (2017). Competitividade e Desempenho das Exportações Brasileira Do Melão. Revista Perspectiva.

Arruda, E. F., Ferreira, R. T., \& Castelar, P. U. de C. (2016). Revista Brasileira de Estudos Regionais e Urbanos (RBERU). Revista Brasileira de Estudos Regionais e Urbanos, 10, 99-126.

Balogh, J. M. ; Jámbor, A. On the duration of comparative advantages: the case of european cheeseindustry Journal article Bulgarian Journal of Agricultural Science 2018 Vol.24 No.1 pp.17 ref.19

Bhattacharya, P. (2018). Determinants of export competitiveness of fresh fruits in India. International Journal of Sustainable Economy. https://doi.org/10.1504/ijse.2019.096567

Bojnec, Š., \& Ferto, I. (2015). Agri-Food Export Competitiveness in European Union Countries. Journal of Common Market Studies, 53(3), 476-492. https://doi.org/10.1111/jcms.12215

Bojnec, Š., \& Fertő, I. (2014). Export competitiveness of dairy products on global markets: The case of the European Union countries. Journal of Dairy Science, 97(10), 6151-6163. https://doi.org/10.3168/jds.2013-7711

CARVALHO, Kaio Henrique Adame de; SILVA, Márcio Lopes da; SOARES, Naisy Silva. Competividade da Polpa de Madeira brasileira no mercado. CERNE , [SI], v. 15, n. 4, p. 383-390, maio de 2015. ISSN 2317-6342. Disponível em: <

http://www.cerne.ufla.br/site/index.php/CERNE/article/view/172 >

Conte, B. P., \& Lermen, N. G. da Silva M.L., da Silva R.A, Conte B. Daniel Arruda Coronel, D. A e Bender Filho R. Análise da competitividade das exportações gaúchas para a china (1999-2013) Revista Ciências Sociais em Perspectiva.

Copetti L.S, Coronel, D.A, Franck, Trevisan (2019): "Competitividade das exportações brasileiras e australianas de algodão: uma análise por meio de indicadores de comércio internacional", Revista Observatorio de la Economía Latinoamericana, (febrero 2019)

Revista de Administração e Negócios da Amazônia, V.10, n.3, set/dez, 2018 ISSN:2176-8366 DOI 10.18361/2176-8366/rara.v10n3p53-72 53

Copetti, L. S., Fries, C. D., \& Coronel, D. A. (2018). Mercado Mundial Do Açúcar: Um Estudo Da Competitividade E Do Grau De Concentração Dos Mercados Brasileiros E Tailandês (20002016). RDE - Revista de Desenvolvimento Econômico, 1(39), 375. https://doi.org/10.21452/rde.v2i40.5553

DUSAN, Šimo \& Ladislav, Mura \& Buleca, Jan. (2016). Assessment of milk production competitiveness of the Slovak Republic within the EU-27 countries. Agricultural Economics (AGRICECON). 62. 482-492. 10.17221/270/2015-AGRICECON.

Esquivias, M. A. (2017) "The Change of Comparative Advantage of Agricultural Activities in East Java Within the Context of Asean Economic Integration", AGRIS on-line Papers in Economics and Informatics, Vol. 9, No. 1, pp. 33 - 47. ISSN 1804-1930.DOI 10.7160/aol.2017.090103.

Frank, A.G.S, Coronel, D. A, Ziani, F.V. Oliveira, G. X, Trevisan, L.V. análise empírica da competitividade do etanol brasileiro (1999-2016). Revista de Administração e Negócios da Amazônia, V.10, n.3, set/dez, 2018 ISSN:2176-8366 DOI 10.18361/2176-8366/rara.v10n3p5372 
Ramos, L. S. (2020). A Mensuração da competitividade nas exportações agropecuárias: uma análise empírica

Franck, A. G. S., Silva, M. L., Silva, R. A., \& Coronel, D. A. (2016). Análise da Competitividade do Mercado Exportador Brasileiro de Café . Desafio Online, 4(3).

Fries, C. D., Conte, B. P., \& Coronel, D. A. (2014). Análise das exportações gaúchas de fumo (20012012). Perspectiva Econômica, 10(1), 1-13. https://doi.org/10.4013/pe.2014.101.01

Fries, C. D., Conte, B. P., \& Coronel, D. A. (2014). Análise das exportações gaúchas de fumo (20012012).

Freitas, K. R. T. de, Costa, J. S. da, Florindo, T. J., \& Duarte, N. D. L. (2014). Competitividade no Mercado de Carne Bovina: Uma comparação a partir das exportações do Brasil e da Argentina no período 2006 a 2013. 53-75.

Franck G. A., S., Ebert, C. D., Abbade, R., \& Coronel, D. A. (2015). 123 4. 3.

Franck G. A, S., Silva, R. A. da silva; D. A. C., \& Silva, M. L. da. (2016). Competitiveness Analysis of the Brazilian Coffee Export Market.

Internacional, I. D. E. C. (2019). Competitividade das exportações brasileiras e australianas de algodão: uma análise por meio de. 1-21.

Jambor, A., Toth, A. T., \& Koroshegyi, D. (2018). Agris on-line Papers in Economics and Informatics The Export Competitiveness of Global Cocoa Traders. IX(February), 294-295. https://doi.org/10.7160/aol.2017.090303

Janaina, J., Marques, S., Araujo, J. M., Lima, S., \& Reis, F. A. (2017). Competitividade das exportações brasileiras de castanha de caju e o efeito da crise 2008. 135-162.

Lazaretti, L. R., Batistella, P., Presotto, E., Teixeira, F. O., \& Feistel, P. R. (2018). Competitividade E Intercâmbio Comercial Do Rio Grande Do Sul: Uma Análise Da Cadeia Produtiva De Carne De Frango (1997 - 2013). Revista de Administração e Negócios Da Amazônia, 10(1), 83. https://doi.org/10.18361/2176-8366/rara.v10n1p83-107

Leua Alpesh,Gamit Pooja, Singh Narendra, Parmar Gautam Export opportunity of agricultural commodities of India: Revealed comparative advantage approach. Indian Journal of Economics and Development. Year : 2017, Volume : 13, Issue : 2a Article DOI : 10.5958/23220430.2017.00156.1

Macedo, R. D., Soares, N. S. (2015). O desempenho das exportações brasileiras de amêndoas de castanha-de-caju entre os anos de 2007 e 2011. 148-162.

Mygre Lopes da Silva, Rodrigo Abbade da Silva, Bruno Pereira Conte, Nadine Gerhardt Lermen, Daniel Arruda Coronel, Reisoli Bender Filho 2015 Revista Ciências Sociais em Perspectiva.

Narayan, S., \& Bhattacharya, P. (2019). Relative export competitiveness of agricultural commodities and its determinants: Some evidence from India. World Development, 117, 29-47. https://doi.org/10.1016/j.worlddev.2018.12.013

Oliveira, M. D. F. L., De Ceped, M. S., \& Bernabéu, R. (2017). Competitiveness analysis of the Portuguese processed tomato sector and development strategies. Agricultural Economics Review, 18(1), 73-82.

OLVAO, R. F.; CAMARA, M. R. G.; SEREIA, V. J.; CALDARELLI, C. E. (2015). Estudo da competitividade internacional do complexo agroindustrial brasileiro de papel e celulose, 1990-2013. XII ENABER - Encontro da Associação Brasileira de Estudos Regionais e Urbanos, (October), 20.

Penha, T. A. M., Alves, H. C. (2019). O DESEMPENHO DAS EXPORTAÇÕES DO MELÃO POTIGUAR E CEARENSE: uma análise de constant market share. Revista de Estudos Sociais, 20(41), 233. https://doi.org/10.19093/res7634 
Ramos, L. S. (2020). A Mensuração da competitividade nas exportações agropecuárias: uma análise empírica

Pires, M. M. Amaral, G.V. Conceição R. L. C Da; Macedo, R.D (2016). O Desempenho das Exportações Brasileiras De Uva: Uma Análise da Competitividade da Região do Vale do São Francisco no Período de 2005 a 2014.

Porter, M. A vantagem competitiva das nações: edição 5 (reimpressão 2017).

Sá Barreto, R. C., \& Novais, J. M. S. (2016). A competitividade internacional do tabaco do sul do Brasil: 1997-2014. Economia \& Região, 4(1), 121. https://doi.org/10.5433/2317-627x.2016v4n1p121

Santos, J. R. P. dos, \& Santos, J. M. dos. (2016). Estudo Da Competitividade Das Exportações De Melão Nos Estados De Rio Grande Do Norte E Ceará. RDE - Revista de Desenvolvimento Econômico, https://doi.org/10.21452/rde.v2i34.3656

Santos, J. L. da S., Sousa, E. P. de, \& Coronel, D. A. (2017). Desempenho Exportador De Couros E Peles Nos Estados Do Nordeste Brasileiro. RDE - Revista de Desenvolvimento Econômico, 1(39), 136. https://doi.org/10.21452/rde.v3i38.5081

Schirigatti, E. L., Silva, J. C. G. L. da, Almeida, A. N. de, Santos, A. J. dos, \& Rucker. (2018). Vantagem Comparativa E Matriz De Competitividade Do Mate Brasileiro E Argentino, No Período De 1997-2011. Ciência Florestal, 28(4), 1807. https://doi.org/10.5902/1980509835360

Shuai, C., \& Wang, X. (2018). Comparative advantages and complementarity of Sino-US agricultural trade: An empirical analysis. Agricultural Economics (Zemědělská Ekonomika), 57(No. 3), 118131. https://doi.org/10.17221/46/2010-agricecon

Silva, M. L. da, Silva, R. A. da, Conte, B. P., Lermen, N. G., Coronel, D. A., \& Filho, R. B. (2019). Análise Da Competitividade Dos Principais Complexos Exportadores Do Agronegócio Gaúcho.

Horizontes Das Ciências Sociais Rurais 3, 20(55), 17-30.

https://doi.org/10.22533/at.ed.3291918022

Souza, S. F. De, Luiz, J., Paulo, J., \& Guedes, M. (2016). Competitividade E Parcela De Mercado Das Exportações Brasileiras De Manga: Uma Análise Do Modelo Constant Market Share. V. Econ. $\mathrm{NE}$, 39-48. Retrieved from https://www.embrapa.br/busca-de-publicacoes//publicacao/1093442/competitividade-e-parcela-de-mercado-das-exportacoes-brasileiras-demanga-uma-analise-do-modelo-constant-market-share

Stankaitytè, B. (2016). Competitiveness of Dairy Products Export To Russia and Alternative Markets. Management Theory and Studies for Rural Business and Infrastructure Development, 38(4), 425-435. https://doi.org/10.15544/mts.2016.34

Stefan, B., \& Imre, F. (2016). Export competitiveness of the European Union in fruit and vegetable products in the global markets. Agricultural Economics (Zemědělská Ekonomika), 62(No. 7), 299-310. https://doi.org/10.17221/156/2015-agricecon

TEODORO, C. B. Gestão e Desenvolvimento em Revista V. 1, N. 1, jan-jun/2017, p. 74-83. ISSN online: 2446-8738 Artigo recebido em: 22/05/2017 Artigo aprovado em: 19/06/2017 A competitividade das cooperativas paranaenses no mercado internacional

Terin, M. ; Yıldırım, i. ; Aksoy, A. ; Sarı, M. M. Academia Agrícola, Bulgária. Competition power of honey export and comparison with balkan countries. Journal article : Bulgarian Journal of Agricultural Science 2018 Vol.24 No.1 pp.17-22 ref.32

Uriarte C., M.; Aparicio, J.; De Pablo-Valenciano, J. (2017). Analysis of Spain's competitiveness in the European tomato market: An application of the Constant Market Share method. Spanish Journal of Agricultural Research, Volume 15, Issue 3, e0113.

https://doi.org/10.5424/sjar/2017153-10629

Valenciano, P., Giacinti Battistuzzi, M. A. (2015). Complexity in world trade of pears | Complejidad 
Ramos, L. S. (2020). A Mensuração da competitividade nas exportações agropecuárias: uma análise empírica

en el comercio mundial de peras. Revista de La Facultad de Ciencias Agrarias, 46(1), 125-141.

Valenciano, P., Uriarte, M. M. C., \& Battistuzzi, M. A. G. (2017). South Africa's competitiveness against its main competitors in the market of pears imported by the EU28. Agrekon, 56(2), 191-204. https://doi.org/10.1080/03031853.2017.1297723

Favaretto, L., Favaretto, J., Graduação, C. De, \& E-mail, U. (2018). 2017 ) Competitiveness of Brazilian exports of pork ( 1999-2017). 155-169.

Van Hoang, V., Tran, K. T., Van Tu, B., Nguyen, V. N., \& Nguyen, A. Q. (2017). Agricultural competitiveness of vietnam by the RCA and the NRCA Indices, and consistency of competitiveness indices. Agris On-Line Papers in Economics and Informatics, 9(4), 53-67. https://doi.org/10.7160/aol.2017.090406

Vanitha, S. M., Kumari, G., \& Singh, R. (2014). Export Competitiveness of Fresh Vegetables in India. International Journal of Vegetable Science, 20(3), 227-234. https://doi.org/10.1080/19315260.2013.789812

Verter, N. (2016). Cocoa export performance in the world's largest producer. Bulgarian Journal of Agricultural Science, 22(5), 713-721.

Vicensotti, J. M., Sanjuan Montebello, A. E., \& Marjotta-Maistro, M. C. (2019). Competitividade brasileira no comércio exterior da carne bovina. Revista IPecege, 5(1), 7-18. https://doi.org/10.22167/r.ipecege.2019.5.7

Zdráhal, I., \& Bečvářová, V. (2018). Entry Into the Common Market of the European Union in Terms of Czech Republic's Foreign Trade with Dairy Products. Acta Universitatis Agriculturae et Silviculturae Mendelianae Brunensis, 66(2), 605-616.

https://doi.org/10.11118/actaun201866020605 